\title{
Suppression of SV40-promoted gene expression by differentiation of preadipose cells
}

\author{
Philippe Djian, Marjorie Phillips, and Howard Green \\ Department of Cellular and Molecular Physiology, Harvard Medical School, Boston, Massachusetts 02115 USA
}

\begin{abstract}
When a plasmid bearing the chloramphenicol acetyltransferase (CAT) gene under the control of an SV40 early promoter is introduced into preadipose or adipose cells of line 3T3-F442A, the promoter directs high levels of transient expression of CAT. However, when the plasmid is introduced into preadipose cells and the cells are then allowed to differentiate into adipose cells, the expression of the CAT gene is suppressed. In this process, the plasmid is not changed detectably in amount, topology, or state of methylation. Stably transformed preadipose cells bearing an integrated plasmid express the transferase, but if the cells are allowed to differentiate, the expression of the gene is similarly suppressed. The decline in CAT activity is associated with a decrease in the transcription rate of the gene. Transcription of a gene coding for neomycin phosphotransferase driven by the SV40 promoter is also greatly diminished by differentiation. Because suppression of CAT does not occur when the gene is under control of a retroviral long terminal repeat (LTR), a specific mechanism exists for the recognition and inactivation of the SV40 early promoter during differentiation.
\end{abstract}

[Key Words: SV40 promoter; suppression of transcription; adipose differentiation]

Received May 4, 1988; revised version accepted August 1, 1988.

3T3-F442A is a fibroblastic cell line able to differentiate into adipocytes with a high frequency (Green and Kehinde 1976). As a result of reprogramming of protein synthesis, in which changes in transcription participate (Bernlohr et al. 1985; Cook et al. 1985; Diian et al. 1985; Doglio et al. 1986), numerous proteins become more abundant and others become less abundant (Sidhu 1979; Spiegelman and Green 1980). In the course of experiments aimed at defining the DNA sequences required for adipocyte-specific activation of genes (Hunt et al. 1986; Ireland et al. 1986; Phillips et al. 1986), we observed that the transient expression of a chloramphenicol acetyltransferase (CAT) gene controlled by the SV40 early promoter was completely suppressed following adipose differentiation. We describe this phenomenon and show that it is a consequence of a decrease in transcription rate and that the viral promoter is the probable target of the differentiation-specific suppression mechanism.

\section{Results}

Transiently transfected preadipocytes and adipocytes support good expression of the SV40-controlled CAT gene

Preadipocytes were grown to confluence in the presence of cat serum. Some cultures were allowed to remain in the preadipose state by feeding them with the same medium. Others were allowed to develop adipose differentiation by cultivating them with medium containing fetal calf serum. After 8 days in the confluent state, both preadipose and adipose cultures were transfected with pSV-CAT (Fig. 1) a derivative of pSV2-CAT (Gorman et al. 1982). Two and a half days later, extracts of both preadipose (Fig. 2, lane 2) and adipose cells (lane 1) contained a high level of CAT activity, indicating that although these cell types are specialized to carry out different functions, both can transcribe the SV40-promoted CAT gene and synthesize the enzyme.

Transient expression of the SV40-controlled CAT gene is almost completely suppressed during adipose differentiation

Preadipose cells were transfected with the plasmid bearing the CAT gene. Half of the cultures were then induced to differentiate by exposure to highly adipogenic fetal calf serum for 7 days. Other cultures were maintained in the preadipose state in the presence of cat serum for the same period. CAT activity measured in the extract of the adipocytes (Fig. 2, lane 3) amounted to $<2 \%$ that of the preadipocyte extract (lane 4). In a similar experiment, the same plasmid was introduced into 3T3-C2 cells, which have a very low susceptibility to adipose differentiation and remain preadipose even in the presence of highly adipogenic fetal calf serum. CAT activity remained high, even after a week of exposure to fetal calf serum. Suppression is therefore a consequence of differentiation itself rather than of exposure to fetal calf serum. 


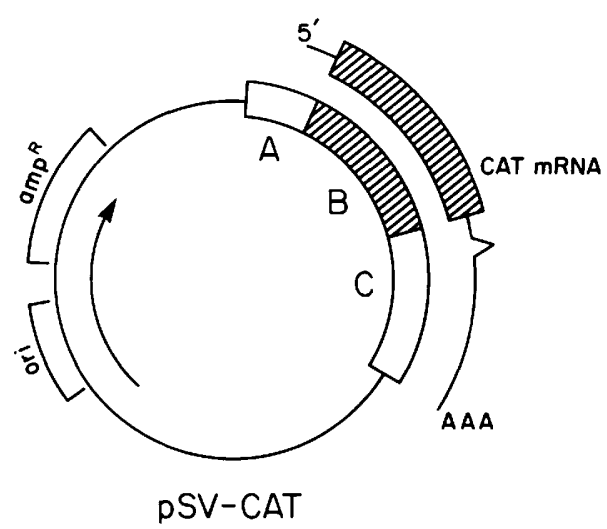

Figure 1. Map of pSV-CAT. (Open blocks) SV40 sequence; (hatched blocks) CAT sequence; (thin line) plasmid sequence. $(A)$ SV40 early promoter; $(B)$ CAT gene; $(C)$ small $t$ intron and poly(A) addition signal of SV40. (ori) Plasmid origin of replication; $\left(\mathrm{amp}^{\mathrm{r}}\right)$ Sequence coding for ampicillin resistance. $(\rightarrow)$ The direction of transcription. The CAT mRNA is shown with its $5^{\prime}$-untranslated region $\left(5^{\prime}\right)$, coding sequence (hatched), spliced small $t$ intron, $3^{\prime}$-untranslated region, and poly(A) tail (AAA).

\section{Adipose differentiation does not suppress transient CAT gene expression by destruction of the nuclear plasmid, alteration of its topology, or extensive methylation}

One known cause for arrest of transcription following transfection with a plasmid is degradation of the plasmid. For example, when CV-1 or L cells were transfected with a supercoiled plasmid, the plasmid became nicked and linearized within $24 \mathrm{hr}$, losing all transcrip-

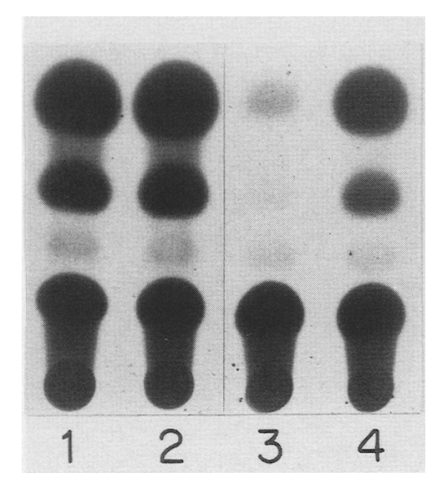

Figure 2. Effect of differentiation on SV40-promoted CAT activity in transiently transfected cells. Adipose cells in medium containing fetal calf serum (lane 1) and preadipose cells in medium containing cat serum (lane 2) were kept in the confluent state for 1 week. Both cell types were then transfected, and the CAT activity measured 2.5 days later. Both have high activity. Several cultures of exponentially growing preadipose cells were transfected and then grown to confluence in medium supplemented with cat serum. In half the cultures, the medium was thereafter supplemented with fetal calf serum to promote adipose differentiation (lane 3). The other half, maintained in the presence of cat serum, remained as preadipose cells (lane 4). The CAT activity, measured 7 days after confluence, was nearly completely suppressed by the process of differentiation. tional activity (Weintraub et al. 1986). To test whether this was the cause of suppression of CAT gene expression in our experiments, we transfected cells before differentiation; some cultures were then allowed to differentiate, and others were maintained in the preadipose state. The plasmid was recovered at different times from the nuclei of adipose and preadipose cultures and electrophoresed in the presence of ethidium bromide at 2.5 $\mu \mathrm{g} / \mathrm{ml}$. At this concentration (Martin et al. 1983), supercoiled plasmid has the fastest migration rate followed by relaxed closed circles (not shown) and linears (Fig. 3A, lanes 1 and 6). Any nicking, which relaxes supercoiled molecules, or linearization should be detected. No modification of the recovered plasmid was observed in either adipose or preadipose cells. Nearly the same amount of supercoiled plasmid was isolated 0,3 , or 7 days after confluence both from preadipocytes expressing CAT activity and adipocytes whose CAT activity was suppressed (Fig. 3A, lanes 1-5).

Because methylation of cytosine residues of $\mathrm{CpG}$ dinucleotides has been implicated in the inactivation of genes, we examined the state of methylation of the recovered plasmid using MspI and its methylation-sensitive isoschizomer HpaII. There are 16 sites in the plasmid, albeit none within the promoter. Four bands were large enough to be resolved by our electrophoresis; their respective sizes were 1916, 740, 500, and $400 \mathrm{bp}$, the latter two of which should actually be doublets $\mid 501$ plus 489 bp and 408 plus 404 bp, respectively). In total, the products of $10 \mathrm{MspI}$ cleavages should be included. The same patterns were generated when plasmid rescued from preadipose and adipose cells at day 7 was cut with either MspI or HpaII (Fig. 3B, lanes 3-4). These patterns were similar to those produced from plasmid obtained directly from bacteria (lane 1) or rescued from recently transfected preadipose cells (lane 2), indicating that none of the sites became methylated. Cytosine methylation could have remained undetected in our experiments if the methylcytosines were present at sites other than the ones detectable with HpaII. Alternatively, if only a small fraction of the introduced plasmid were transcriptionally active and if this small fraction were the sole target for cytosine methylation, the methylation could have been overlooked.

\section{In stably transformed cells SV40- but not Moloney LTR-promoted CAT expression is suppressed by differentiation}

In the experiments described above, we assumed that CAT gene transcription originated from the free nuclear plasmid rescued, because no selection for a chromosomal integrated gene was applied. To determine whether a stably integrated gene would be similarly suppressed by differentiation, we constructed stable transformants and measured CAT activity before and after differentiation. The first cell line we tested [F442A(1)SV] was produced by cotransfection with plasmids containing the CAT and neomycin-resistance genes, each under the control of an SV40 early promoter. Like the 


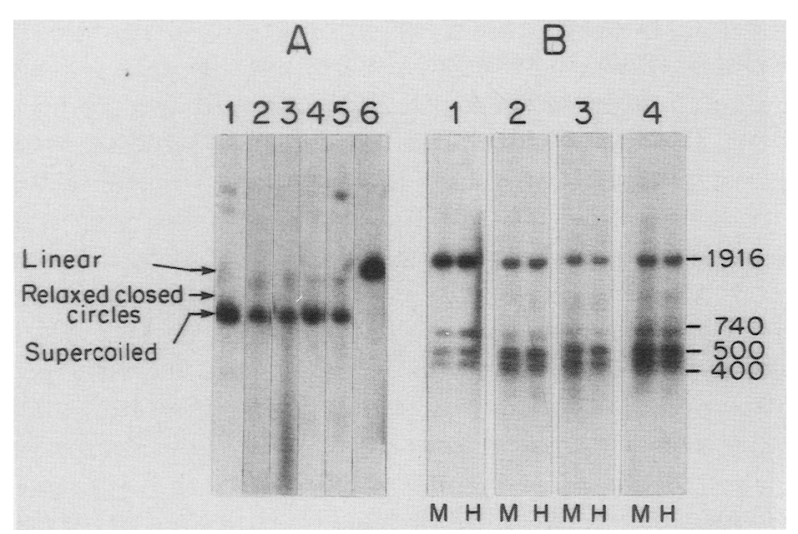

Figure 3. Amount, topology, and methylation of the rescued nuclear plasmids. Preadipose cells were transfected with pSVCAT and then allowed to differentiate. After varying intervals, plasmid was recovered from nuclear DNA by the method of Hirt (1967). One fifth of the recovered DNA $(\sim 5 \mathrm{pg})$ was loaded in each lane of an agarose gel. DNA was transferred to nitrocellulose and hybridized with nick-translated pSV-CAT. The blot was exposed to film for $2 \mathrm{hr}$. (A) Topology of rescued pSV-CAT. (Lane 1) Plasmid used for transfection. All is in supercoiled form; no relaxed circles were detected. Faint bands with mobility between those of linear and supercoiled forms probably represent concatamers as they were c snverted to linear form by BamHI. (Lane 2) Plasmid recovered from adipose cells after a 3-day period of differentiation. (Lane 3) Plasmid recovered from preadipose cells at the same time. (Lane 4) Plasmid recovered from adipose cells after a 7-day period of differentiation. (Lane 5) Plasmid recovered from preadipose cells at the same time. (Lane 6) Starting plasmid linearized with BamHI. The amount and topological state of the nuclear plasmid remained unchanged during the differentiation process. $(B)$ Methylation status of rescued pSV-CAT. Plasmid was cut with either HpaII (H) or MspI (M). (Lane 1) Plasmid used for transfections; (Lane 2) Plasmid rescued at confluence from preadipose cells; (Lane 3) Plasmid rescued from adipose cells after differentiation; (Lane 4) Plasmid recovered from preadipose cells at the same time 17 days after confluence). Four bands were resolved after digestion. They correspond to DNA fragments of 1916, 740, 500, and 400 bp. The latter two are doublets. HpaII and MspI generated fragments of similar size, indicating that all the sites detected remained unmethylated.

transiently transfected cells, stable transformants showed high CAT activity in preadipocytes, and the activity was reduced to $3-8 \%$ after adipose differentiation (Table 1). In contrast, when we tested cell line F442A(1) Mol which possesses an integrated CAT gene under the control of the Moloney virus long terminal repeat (LTR), CAT activity was not diminished by differentiation. Because these two cell lines differ only in the nature of the viral promoter, it seems that the DNA sequence responsible for differentiation-dependent suppression lies within the SV40 promoter.

\section{Adipose differentiation suppresses transcription of the CAT gene}

To assess whether transcriptional changes were responsible for differences in CAT activities resulting from the process of differentiation, we labeled nuclear transcripts in a nuclear run-on assay. Because we observed high levels of hybridization to pUC13 sequences in cells transformed with the whole plasmid, we made another stable transformant with CAT and neomycin phosphotransferase genes from which plasmid sequences had been removed. This line [F442A(1)SV(Pst)] did not hybridize with pUC13 sequence and exhibited differentiation-dependent suppression of CAT activity of a magnitude similar to that of $\mathrm{F} 442 \mathrm{~A} / 1) \mathrm{SV}$. To assay the products of nuclear run-on experiments, labeled transcripts were hybridized to plasmids containing the following insertions: CAT (pSV-CAT); neomycin phosphotransferase $\left(\mathrm{pSV}_{2}\right.$-neo); glycerophosphate dehydrogenase (pGPD), which increases strikingly in amount during adipose differentiation (Pairault and Green 1979; Wise and Green 1979; Spiegelman et al. 1983); actin (pAct), whose corresponding mRNA is present at high levels in both adipose and preadipose cells (Spiegelman et al. 1983); and albumin (pAlb), whose corresponding mRNA is absent from adipose and preadipose cells. In two separate experiments there was a complete or nearly complete suppression of both CAT and neomycin phosphotransferase gene transcription (Table 2), indicating that in permanently transformed cells most, if not all, the decline in CAT activity that accompanies adipose differentiation is due to a decrease in the transcription level of the gene.

\section{Discussion}

When a recombinant plasmid containing a CAT gene controlled by an SV40 early promoter enters the nucleus of either a preadipose cell or an adipose cell after it is formed by differentiation, the viral element promotes transcription of the bacterial gene and results in high activity of the corresponding enzyme in both cell types. If, following transfection, preadipocytes are induced to differentiate SV40-controlled enzyme activity disappears almost completely. This effect clearly results from exposure of the plasmid to cellular changes that accompany the nuclear reprogramming during the differentiation.

During adipose differentiation, numerous polypeptides disappear or decrease in amount (Sidhu 1979; Spie-

Table 1. CAT activity in cells stably transformed with $p S V$ CAT or pMol-CAT

\begin{tabular}{clcr}
\hline & \multicolumn{3}{c}{$\begin{array}{c}\text { Acetylated chloramphenicol } \\
\text { (cpm/ } \mu \text { g protein) }\end{array}$} \\
\cline { 2 - 4 } Experiment & cell line & preadipose & adipose \\
\hline 1 & F442A(1)SV & 8200 & 220 \\
2 & F442A(1)SV & 2600 & 220 \\
2 & F442A(1)Mol & 1850 & 3070 \\
\hline
\end{tabular}

Cells stably transformed by pSV-CAT [F442A(1)SV] or pMolCAT [F442A/1) Mol] were kept confluent for 10 days as preadipose cells in cat serum or as adipose cells in fetal calf serum. CAT activity of cell extracts was then measured. 
Djian et al.

Table 2. Incorporation of $\left.\right|^{32} P J U T P$ into specific transcripts before and after differentiation

\begin{tabular}{lcc}
\hline Gene & Preadipose & Adipose \\
\hline CAT & 2.4 & 0.1 \\
Neomycin & & \\
phosphotransferase & 4.8 & 0 \\
Actin & 4.2 & 3.3 \\
GPD & 0 & 0.5 \\
\hline
\end{tabular}

Nuclear RNA was isolated from F442A(1)SV(Pst) cells 10 days after confluence. Plasmids were applied to nitrocellulose as dots; the nitrocellulose was then hybridized with RNA containing $3 \times 10^{7} \mathrm{cpm}$ RNA for 2 days and exposed to film for 1-2 days. Dots were scanned with a laser densitometer. The values were derived from the maximum height of the peak, as some dots were uneven. The optical density of the albumin dot $(0.2)$ was considered to be the background value and was subtracted from all other values.

gelman and Green 1980). The best studied example is actin. mRNA levels decrease to one-half or one-third during adipose conversion (Spiegelman et al. 1983) and this is accompanied by a concomitant decrease in transcription (Cook et al. 1985). Other cytoskeletal proteins are suppressed to a greater extent than actin /Spiegelman and Farmer 1982), but transcription rates have not yet been examined. The developing adipocyte evidently suppresses to some extent the function of numerous genes that are unnecessary for its new functions. Because suppression extends even to exogenous genes, some general mechanism may be required for this purpose during differentiation. The SV40-CAT fusion gene appears to be treated as such an unnecessary function and is suppressed along with cellular genes.

\section{How does the cell recognize the CAT gene as an unnecessary function?}

We have described differentiation-dependent suppression of CAT gene and neomycin phosphotransferase gene transcription, both under control of an SV40 early promoter. In contrast to these two genes, the expression of the CAT gene under control of a Moloney leukemia virus LTR was not affected by adipose conversion. This provides strong evidence that the 323-bp sequence encompassing the SV40 promoter specifically loses its ability to promote transcription of the nearby reporter gene. Inactivation of transcription of this gene occurs only if it is present while the cell undergoes adipose conversion; thereafter, the gene is stably inactivated. This is reminiscent of the action of 5-azacytidine, which leads to activation of genes, presumably by demethylation (Taylor and Jones 1979). However, we were unable to show that any methylation had occurred in the plasmid as a result of cell differentiation. Alternatively, a protein with the properties of an antitranscription factor could be responsible. As we observed that mature adipose cells support good transcription of exogenous genes, such an antitranscription protein would only be made during the process of differentiation. Its interaction with DNA would have to be long lived, much like the stable complexes formed to maintain transcription of the 5S rRNA genes (Bogenhagen et al. 1982).

In permanent transformants, the SV-neo gene was cotransfected with the SV-CAT gene. The two were presumably ligated together, forming a concatamer, and integrated together in the chromosome (Perucho et al. 1980). The transformants that we used were pools of hundreds of different clones surviving selection, each clone presumably having integrated a plasmid at different sites. Therefore, a precise chromosomal location of the exogenous sequences is not likely to be required for inactivation by differentiation. However, it is possible that a rare transformant might not turn off CAT and neomycin phosphotransferase transcription if the gene were integrated in or near a transcriptionally active region (Barklis et al. 1986). Such clones would remain undetected in the experiments described but might be selected for by allowing the stably transformed cell lines to differentiate, selecting with G418 and isolating colonies of adipocytes resistant to the drug.

In preimplantation mouse embryos, there is no transcription of injected SV40 (Jaenisch and Mintz 1974) or murine leukemia virus (Jahner et al. 1982). This transcription block persists, because no infectious viral particles can be rescued from tissues of the infected mouse for as long as 5 months after birth. After infection of a postimplantation embryo, the same virus is transcribed to high levels, transcription persists throughout development, and infectious viral particles are produced even in the adult animal. Similarly, inactivation of SV40-promoted gene expression during development has been described in transgenic mice bearing the SV40 early genes (Brinster et al. 1984). The inactivation was somewhat specific because a metallothionein promoter directed high levels of gene expression in a wide variety of tissues. The SV40 transgene was probably inactivated very early after its injection and may never have been expressed at all.

In the preimplantation embryo, inactivation of the retrovirus is thought to be a consequence of de novo methylation of viral DNA. This is in contrast to our results and those of Brinster et al. (1984) in which there was no correlation between the methylation status of the viral DNA and its expression. Therefore, more than one mechanism can lead to specific suppression of gene transcription at certain stages of differentiation.

Repression of viral expression has also been observed in cultured cells: a number of undifferentiated murine teratocarcinoma cell lines do not support transcription of a variety of RNA or DNA viruses, including SV40 (Swartzendruber and Lehman 1974; Teich et al. 1977; Barklis et al. 1986). Differentiation of the infected cells does not reactivate expression of the repressed viral genome. However, if the teratoma cells are infected after differentiation, vigorous transcription of the viral DNA is observed.

The inactivation of the SV40-directed CAT gene seems to resemble normal processes of gene inactivation during differentiation more closely than the other ex- 
amples cited, because CAT gene expression was well established in the preadipose cell prior to the differentiation. Although far more attention has been devoted to the problem of activation of gene expression during differentiation, it seems likely that the suppression of gene expression in differentiation is of comparable importance, as it makes possible the specialization of the cell for new functions.

\section{Methods}

Enzymes and other materials were obtained from the following sources: Restriction enzymes were obtained from New England Biolabs; T4 DNA ligase and Klenow polymerase were from Amersham; nitrocellulose filters and ion-exchange minicolumns (Elutip) were from Schleicher and Schuell; ribonucleotides, creatine phosphate, and creatine kinase were from Pharmacia; G418 (Geneticin) was from GIBCO; radioactive UTP and chloramphenicol were from New England Nuclear.

\section{Cell lines}

The cell line used in these experiments, 3T3-F442A (1), was derived from 3T3-F442A in the following way. A confluent culture of 3T3-F442A containing numerous adipose cells (7 days after addition of fetal calf serum) was disaggregated with trypsin. Under the microscope, a single young adipocyte containing lipid droplets was isolated with the aid of an elongated pasteur pipette (Barrandon and Green 1985) and inoculated into a $35-\mathrm{mm}$ petri dish. At this early stage of adipose conversion, the differentiated state is sometimes reversible (Negrel et al. 1978 ). About $10 \%$ of the young adipocytes isolated gave rise to colonies that soon lost all evidence of the adipose phenotype. Three clones were then tested for their ability to redifferentiate, and all were found to have a higher susceptibility to adipose conversion than 3T3-F442A. F442A (1), one of such clones, was used in all experiments.

\section{Cell culture}

All the cultures were grown in Dulbecco-Vogt modified Eagle's medium supplemented with $7.5 \%$ cat serum and $1 \%$ calf serum. As cat serum is virtually devoid of adipogenic activity, the cell population remains purely preadipose (Kuri-Harcuch and Green 1978). After reaching confluence, the cultures were either maintained as preadipocytes in this medium or were induced to differentiate by changing the serum supplement of the medium to $10 \%$ fetal calf serum and by adding insulin to $5 \mu \mathrm{g} / \mathrm{ml}$.

\section{Plasmids}

Two plasmids containing the CAT gene, pSV-CAT and pMolCAT, were constructed for use in transfections. Both were derived from pl06 (Gilman et al. 1986), which includes, in pUC13, a promoterless CAT gene followed by SV40 small $t$ intron and polyadenylation signals. For construction of the pSVCAT plasmid, the SV40 early promoter was isolated as a 323-bp piece by digesting pSV2-CAT (Gorman et al. 1982) with PvuII and HindIII, blunted, and inserted in the SmaI site of p106. A map of pSV-CAT is shown in Figure 1. pMol-CAT, kindly provided by N. Speck (MIT), contains the Moloney leukemia virus LTR, excised as a Sau3A-KpnI piece, and substituted for the SV40 early promoter in a plasmid otherwise identical to pSVCAT. Three additional plasmids were used in transcription assays: pGPD contains a glycerophosphate dehydrogenase
cDNA, pAct contains an actin cDNA, and pAlb an albumin cDNA. The GPD and actin cDNAs have been described by Spiegelman et al. (1984), and the albumin cDNA by Sellem et al. (1984). All three were subcloned into the PstI site of pUC18.

\section{Transient transfection and CAT assay}

The plasmid DNA was precipitated with calcium phosphate (Gorman 1985). An amount of DNA found to give the highest CAT activity, $30-50 \mu \mathrm{g}$, was used in all experiments. The precipitate was left on the cells for $4 \mathrm{hr}$; the cultures were then washed with phosphate-buffered saline, and a 3.5 -min glycerol shock was performed. For transfection of rapidly dividing preadipocytes, cultures were used when two-thirds confluent. For transfections of adipose and resting preadipose cells, one culture of each, confluent for 7 days, was disaggregated with trypsin; $2.5 \times 10^{6}$ cells were mixed with the DNA precipitate and replated on the same size dish. Addition of the precipitate to a cell suspension, rather than an adherent monolayer, and replating the cells at a density such that the cultures were barely confluent yielded a higher transfection efficiency than could be obtained from dense surface cultures of resting cells.

CAT activity was measured as described by Gorman (1985) using $250 \mu \mathrm{g}$ protein. The protein concentration of the cytoplasmic extract was determined by the Bio-Rad Coomassie dye binding assay (Sedmak and Grossberg 1977).

\section{Recovery of the nuclear plasmid and DNA blots}

Nuclei of transfected cells were prepared by resuspending the cells in buffer $(15 \mathrm{~mm}$ Tris at $\mathrm{pH} 7.5,15 \mathrm{~mm} \mathrm{NaCl}, 1 \mathrm{~mm}$ EDTA, $0.5 \mathrm{~mm}$ spermidine, $0.15 \mathrm{~mm}$ spermine) and homogenizing with 15 strokes in the presence of $0.2 \%$ NP-40 using a Dounce homogenizer. The nuclei were then centrifuged at $2500 \mathrm{~g}$ for $3 \mathrm{~min}$. Plasmid DNA was separated from chromosomal DNA by lysing the nuclei with SDS and precipitating the chromosomal DNA with $\mathrm{NaCl}$ according to Hirt (1967). The supernatant containing the free nuclear plasmid was extracted once with an equal volume of phenol/chloroform and once with chloroform and precipitated with two volumes of isopropanol for at least $2 \mathrm{hr}$ at $-20^{\circ} \mathrm{C}$. For cutting with restriction enzymes, the DNA was further purified by passage through an ion-exchange minicolumn (Elutip), followed by ethanol precipitation. For determination of the amount and state of plasmid, a fraction of the purified Hirt supernatant obtained from one 100$\mathrm{mm}$ dish was electrophoresed through a $1 \%$ agarose gel; the DNA was transferred to nitrocellulose (Thomas 1980) and hybridized to plasmid labeled by nick-translation (Rigby et al. 1977).

\section{Stable transformants}

Stably transformed cells were obtained by cotransfecting $0.5 \mu \mathrm{g}$ of a plasmid containing the neomycin resistance gene, pSV2neo (Gorman 1985), and 5-10 $\mu$ g of pSV-CAT or pMol-CAT. Plasmids were linearized with HindIII and then used to transfect a $100-\mathrm{mm}$ dish of two-thirds confluent, rapidly dividing preadipocytes. Three cell lines were constructed: Cells that had stably integrated the plasmids pSV-CAT or pMol-CAT were designated as F442A(1)SV or F442A(1)Mol. The third cell line, F442A(1)SV(Pst), was transformed with the SV40-CAT gene from which all plasmid sequences were removed. For this purpose, cells were cotransfected with a $2.6-\mathrm{kb}$ Pst fragment derived from pSV-CAT, containing the SV40 early promoter, the bacterial CAT gene, and most of the SV40 $3^{\prime}$-processing signals (including two polyadenylation signals), together with a $3.4-\mathrm{kb}$ 
AccI/EcoRI fragment of pSV2-neo. Three days after transfection, the cells were diluted 10 -fold into medium containing $\mathrm{G} 418$ at $1 \mathrm{mg} / \mathrm{ml}$, and selection was maintained for 9 days. A few hundred large colonies of resistant cells were then visible. These were pooled and used for experiments.

\section{Nuclear transcription}

Transcription was measured in the resulting F442A(1)SV(Pst) cell line lacking plasmid sequence by isolating nuclei and labeling nascent transcripts with [32P]UTP in a nuclear run-on assay (Groudine et al. 1981; Hofer et al. 1981; Diian et al. 1985). Ten dishes of adipocytes and 30 of preadipocytes were used for each experiment, yielding about $5 \times 10^{7}$ nuclei and $6 \times 10^{7}$ cpm and $3 \times 10^{7} \mathrm{cpm}$, respectively, in nuclear RNA.

Transcripts were labeled in a $10-\mathrm{min}$ reaction. Nuclei were then treated with DNase I and lysed with SDS and proteinase $K$. The nuclear preparation was extracted three times with phenol/chloroform, and the transcripts were separated from unincorporated nucleotides by TCA precipitation. The precipitate was collected by centrifugation for $15 \mathrm{~min}$ in an Eppendorf centrifuge, dissolved and reprecipitated with ethanol. After a second treatment with DNase I, followed by phenol/chloroform extractions, the transcripts were again precipitated with ethanol.

The proportion of a specific transcript in adipose and preadipose nuclear preparations was determined by hybridizing a constant number of counts $\left(3 \times 10^{7}\right)$ to $5 \mu \mathrm{g}$ of plasmid containing the complementary sequence dotted on a nitrocellulose filter (Kafatos et al. 1979). The intensity of the radioactive spot obtained after hybridization was quantitated by laser densitometry after exposure of the filter to film for one day.

\section{Acknowledgments}

These investigations were aided by grants from the NIDDKD and the National Cancer Institute.

\section{References}

Barklis, E., R.C. Mulligan, and R. Jaenisch. 1986. Chromosomal position or virus mutation permits retrovinus expression in embryonal carcinoma cells. Cell 47: 391-399.

Barrandon, Y. and H. Green. 1985. Cell size as a determinant of the clone-forming ability of human keratinocytes. Proc. Natl. Acad. Sci. 82: 5390-5394.

Bernlohr, D.A., M.A. Bolanowski, T.J. Kelly, Jr., and M.D. Lane. 1985. Evidence for an increase in transcription of specific mRNAs during differentiation of $3 \mathrm{~T} 3-\mathrm{L} 1$ preadipocytes. $J$. Biol. Chem. 260: 5563-5567.

Bogenhagen, D.F., W.M. Wormington, and D.D. Brown. 1982. Stable transcription complexes of Xenopus 5S RNA genes: A means to maintain the differentiated state. Cell 28: 413421.

Brinster, R.L., H.Y. Chen, A. Messing, T. VanDyke, A.J. Levine, and R.D. Palmiter. 1984. Transgenic mice harboring SV40 T-antigen genes develop characteristic brain tumors. Cell 37: 367-379.

Cook, K.S., C.F. Hunt, and B.M. Spiegelman. 1985. Developmentally regulated mRNAs in 3T3-adipocytes: Analysis of transcriptional control. J. Cell Biol. 100: 514-520.

Diian, P., M. Phillips, and H. Green. 1985. The activation of specific gene transcription in the adipose conversion of $3 \mathrm{~T} 3$ cells. J. Cell. Physiol. 124: 554-556.

Doglio, A., C. Dani, P. Grimaldi, and G. Ailhaud. 1986. Growth hormone regulation of the expression of differentiation-dependent genes in preadipocyte Obl771 cells. Biochem. J. 238: $123-129$.

Gilman, M.Z., R.N. Wilson, and R.A. Weinberg. 1986. Multiple protein-binding sites in the $5^{\prime}$-flanking region regulate $c$-fos expression. Mol. Cell. Biol. 6: 4305-4316.

Gorman, C.M. 1985. High efficiency gene transfer into mammalian cells. In DNA cloning, a practical approach (ed. D.M. Glover), vol. 1, pp. 143-190. IRL Press, Oxford.

Gorman, C.M., L.F. Moffat, and B.H. Howard. 1982. Recombinant genomes which express chloramphenicol acetyltransferase in mammalian cells. Mol. Cell. Biol. 2: 1044-1051.

Green, H. and O. Kehinde. 1976. Spontaneous heritable changes leading to increased adipose conversion in 3T3 cells. Cell 7: 105-113.

Groudine, M., M. Peretz, and H. Weintraub. 1981. Transcriptional regulation of hemoglobin switching in chicken embryos. Mol. Cell. Biol. 1: 281-288.

Hirt, D. 1967. Selective extraction of polyoma DNA from infected mouse cell cultures. J. Mol. Biol. 26: 365-369.

Hofer, E., R. Hofer-Warbinek, and J.E. Darnell, Jr. 1982. Globin RNA transcription: A possible termination site and demonstration of transcriptional control correlated with altered chromatin structure. Cell 29: 887-893.

Hunt, C.F., J.H.-S. Ro, D.E. Dobson, H.Y. Min, and B.M. Spiegelman. 1986. Adipocyte P2 gene: Developmental expression and homology of $5^{\prime}$-flanking sequences among fat cellspecific genes. Proc. Natl. Acad. Sci. 83: 3786-3790.

Ireland, R.C., M.A. Kotarski, L.A. Johnston, U. Stadler, E. Birkenmeier, and L.P. Kozak. 1986. Primary structure of the mouse glycerol-3-phosphate dehydrogenase gene. $I$. Biol. Chem. 261: 11779-11785.

Jaenisch, R. and B. Mintz. 1974. Simian virus 40 DNA sequences in DNA of healthy adult mice derived from preimplantation blastocysts injected with viral DNA. Proc. Natl. Acad. Sci. 71: 1250-1254.

Jahner, D., H. Stuhlmann, C.L. Stewart, K. Harbers, J. Lohler, I. Simon, and R. Jaenisch. 1982. De novo methylation and expression of retroviral genomes during mouse embryogenesis. Nature 298: 623-628.

Kafatos, F.C., C.W. Jones, and A. Efstratiadis. 1979. Determination of nucleic acid sequence homologies and relative concentrations by a dot hybridization procedure. Nucleic Acids Res. 7: 1541-1552.

Kuri-Harcuch, W. and H. Green. 1978. Adipose conversion of 3 T3 cells depends on a serum factor. Proc. Natl. Acad. Sci. 75: 6107-6109.

Martin, S.R., W.K. McCoubrey, Jr., B.L. McConaughy, L.S. Young, M.D. Been, B.J. Brewer, and J.R. Champoux. 1983. Multiple forms of rat liver type I topoisomerase. Methods Enzymol. 100: 137-144.

Negrel, R., P. Grimaldi, and G. Ailhaud. 1978. Establishment of preadipocyte clonal line from epididymal fat pad of ob/ob mouse that responds to insulin and to lipolytic hormones. Proc. Natl. Acad. Sci. 75: 6054-6058.

Pairault, J. and H. Green. 1979. A study of the adipose conversion of suspended $3 \mathrm{~T} 3$ cells by using glycerophosphate dehydrogenase as differentiation marker. Proc. Natl. Acad. Sci. 76: $5138-5142$.

Perucho, M., D. Hanahan, and M. Wigler. 1980. Genetic and physical linkage of exogenous sequences in transformed cells. Cell 22: 309-317.

Phillips, M., P. Djian, and H. Green. 1986. The nucleotide sequence of three genes participating in the adipose differentiation of 3T3 cells. J. Biol. Chem. 261: 10821-10827.

Rigby, P.W.J., M. Dieckmann, C. Rhodes, and P. Berg. 1977. La- 
belling deoxyribonucleic acid to high specific activity in vitro by nick translation with DNA polymerase I. $/$. Mol. Biol. 113: 237-251.

Sedmak, J.J. and S.E. Grossberg. 1977. A rapid, sensitive and versatile assay for protein using Coomassie brilliant blue G250. Anal. Biochem. 79: 544-552.

Sellem, C.H., A. Gal, and J.M. Sala-Trepat. 1984. Selective detection of rat and mouse specific albumin and $\alpha$-fetoprotein mRNA molecules under highly stringent hybridization conditions. Arch. Biochem. Biophys. 229: 226-236.

Sidhu, R.W. 1979. Two-dimensional electrophoretic analyses of proteins synthesized during differentiation of 3T3-L1 preadipocytes. I. Biol. Chem. 254: 11111-11118.

Spiegelman, B.M. and H. Green. 1980. Control of specific protein biosynthesis during the adipose conversion of $3 \mathrm{~T} 3$ cells. J. Biol. Chem. 255: 8811-8818.

Spiegelman, B.M. and S.R. Farmer. 1982. Decreases in tubulin and actin gene expression prior to morphological differentiation of 3T3 adipocytes. Cell 29: 53-60.

Spiegelman, B.M., M. Frank, and H. Green. 1983. Molecular cloning of mRNA from $3 \mathrm{~T} 3$ adipocytes. I. Biol. Chem. 258: 10083-10089.

Swartzendruber, D.E. and J.M. Lehman. 1974. Neoplastic differentiation: Interaction of simian virus 40 and polyoma virus with murine teratocarcinoma cells in vitro. $J$. Cell. Physiol. 85: 179-188.

Taylor, S.M. and P.A. Jones. 1979. Multiple new phenotypes induced in $10 \mathrm{~T} 1 / 2$ and $3 \mathrm{~T} 3$ cells treated with 5-azacytidine. Cell 17: 771-779.

Teich, N.M., R.A. Weiss, G.R. Martin, and D.R. Lowy. 1977. Virus infection of murine teratocarcinoma stem cell lines. Cell 12: 973-982.

Thomas, P.S. 1980. Hybridization of denatured RNA and small DNA fragments transferred to nitrocellulose. Proc. Natl. Acad. Sci. 77: 5201-5205.

Weintraub, H., P.F. Cheng, and K. Conrad. 1986. Expression of transfected DNA depends on DNA topology. Cell 46: 115122.

Wise, L.S. and H. Green. 1979. Participation of one isozyme of cytosolic glycerophosphate dehydrogenase in the adipose conversion of 3T3 cells. J. Biol. Chem. 254: 273-275. 


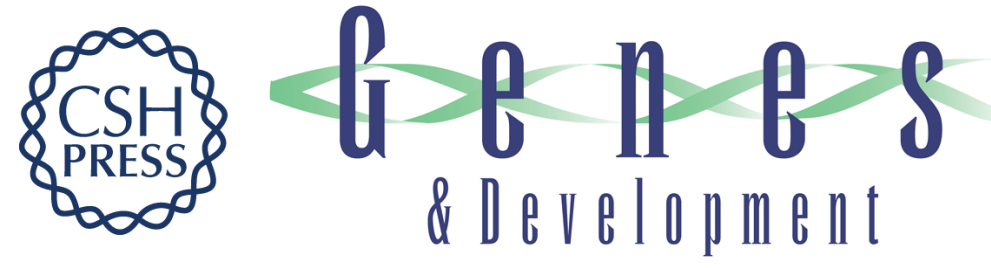

\section{Suppression of SV40-promoted gene expression by differentiation of preadipose cells.}

P Djian, M Phillips and $\mathrm{H}$ Green

Genes Dev. 1988, 2:

Access the most recent version at doi:10.1101/gad.2.10.1251

References This article cites 38 articles, 19 of which can be accessed free at:

http://genesdev.cshlp.org/content/2/10/1251.full.html\#ref-list-1

License

Email Alerting

Service

Receive free email alerts when new articles cite this article - sign up in the box at the top right corner of the article or click here.

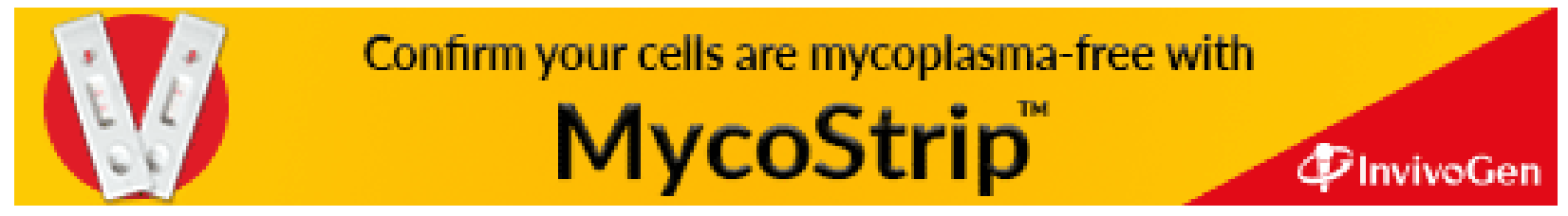

